\title{
Multiple secondary malignancies following radiation therapy for testicular cancer
}

\author{
Sam Neufeld, MD; Tadeusz Kroczak, MD; Darrel Drachenberg, MD
}

University of Manitoba, Winnipeg, MB, Canada

Cite as: Can Urol Assoc J 2015;9(11-12):E908-9. http://dx.doi.org/10.5489/cuai.3396 Published online December 14, 2015.

\section{Abstract}

Testicular germ cell tumours (TGCT) are a rare malignancy that affect primarily young men. We present an interesting case of nonseminoma testicular cancer treated with external beam radiation therapy (RT), which subsequently resulted in two separate secondary malignancies decades after initial treatment.

\section{Case report}

At the age of 16 , the patient underwent surgical correction of bilateral undescended testicles. Ten years later, he was found to have a left testicular mass and underwent a left radical inguinal orchiectomy revealing a malignant teratoma. Surgery and 25 rounds of adjuvant RT resulted in cure. He has been managed uneventfully with testosterone throughout his adult life due to an atrophic right testicle.

Forty four (44) years after orchiectomy and RT, the patient presented to the emergency department with gross hematuria and flank pain. A computed tomography (CT) scan was performed, demonstrating a $2.8 \times 1.7 \mathrm{~cm}$ mass in the renal pelvis consistent with urothelial carcinoma, and a small pulmonary nodule was noted in the lower right lung. Cystoscopy revealed no evidence of lower tract pathology. The patient underwent a laparoscopic left radical nephroureterectomy and retroperitoneal lymph node dissection with endoscopic bladder cuff excision. Pathology revealed a pT1b, N1, MX, high-grade urothelial tumour with focal necrosis. Three of 11 nodes were positive for urothelial carcinoma; lymphovascular invasion was not noted.

In light of the poor prognosis and high risk of recurrence, adjuvant chemotherapy of cisplatin/gemtabicine was offered, but was declined by the patient. The patient recovered quite well apart from noting intermittent hematochezia that began approximately 10 weeks after his surgery. Follow up CT scan performed two months after surgery identified enlargement of the small pulmonary nodule from 5 to 8 $\mathrm{mm}$, along with a new $6 \mathrm{~mm}$ nodule. A soft tissue mass at the recto-sigmoid junction measuring $2.2 \times 2.2 \mathrm{~cm}$ was also identified. Potential treatment options were discussed with the patient, including the fact that worsening findings on subsequent scans would preclude surgical management.

The pulmonary and rectal lesions were identified again three months later. At this time, diffuse thickening of the psoas muscle at the level of the left renal bed and suspicious aortocaval and para-aortic lymph nodes were also noted. Colonoscopy identified a $7 \mathrm{~cm}$ mass approximately 7 $\mathrm{cm}$ from the anus consistent with leiomyosarcoma. Positron emission tomography (PET) scan identified diffuse disease, including the left psoas and pulmonary nodules, as well as cervical and para-aortic lymph nodes. It was unclear whether the lymph nodes and pulmonary nodules represented metastasis from an urothelial or mesenchymal tumour.

The patient was averse to any kind of colostomy and would only consent to anterior resection of the tumour. The patient underwent laparascopic biopsy of a single retroperitoneal lymph node that identified metastatic urothelial carcinoma. The procedure was then converted to an open laparotomy and lower anterior resection of the rectum was performed. Pathologic analysis determined the rectal mass to be a T1, N0, M0, high-grade leiomyosarcoma with negative margins. The lymph node biopsy confirmed the intraoperative diagnosis of metastatic urothelial carcinoma, for which the patient received six cycles of carboplatin/gemcitabine.

Approximately two months after completion of the sixth cycle, the patient began experiencing numbness in his left leg. CT scan showed worsening metastatic disease in the left psoas muscle extending into the vertebral foramen at L2-L3 for which he received 30 Gy in 15 fractions of palliative radiation and was started on nab-paclitaxel. At the time of this report, the patient was alive and tolerating this regimen relatively well. 


\section{Discussion}

Testicular cancer is the most common cancer diagnosis in men aged 20 to 39, with incidence peaking between 25 and 34 years of age. ${ }^{1}$ As young men are typically affected, they are more prone to developing long-term complications from treatment and this must be considered. ${ }^{1}$ Although the etiology of TGCTs is not well understood, a number of risk factors have been documented. Among these, cryptorchidism has consistently been found to confer the greatest overall risk of developing TGCT. ${ }^{2}$ Since the era when this patient was treated, the management of TGCTs has evolved significantly. The advent of platinum-based chemotherapy regimens has decreased reliance on RT and large-dose chemotherapy regimens. However, into the late 70s, RT was still considered a viable treatment option for malignant testicular teratomas. ${ }^{3,4}$ The advent of platinum-based therapy has seen five-year survival rates improve from $83 \%$ to approximately $96 \%$, with fewer long-term complications. ${ }^{5}$

The secondary malignancies developed by this patient have been well documented following radiotherapy. Both urothelial carcinoma and soft tissue sarcomas are known to occur after treatment with radiotherapy. ${ }^{6}$ Both diseases tend to present as high-grade in the post-radiation setting. In a study of patients who underwent RT for prostate cancer, Shah et al noted an increase in the rates of urothelial carcinoma, but also an increased likelihood of presenting with high-grade disease and sarcomatoid features. ${ }^{7}$ Similarly, RT-induced sarcomas are typically high-grade, with a tendency toward distant metastasis and local recurrence following resection. ${ }^{8}$

The risk of secondary malignancy following RT is related to overall survival time. Travis et al showed that the relative risk of a second malignancy in survivors of testicular cancer is inversely correlated with age at diagnosis. ${ }^{9} \mathrm{~A}$ study by Zagars et. al. showed that the relative risk of death due to second malignancy is $1.9 .^{10}$ They also showed that the increased risk is only significant 15 years following treatment. ${ }^{9,10} \mathrm{~A}$ very similar trend was shown by Murray et al, who found an average latency of approximately 15 years in the development of post-RT sarcoma. ${ }^{11}$

Despite long-term side effects, RT remains a mainstay in the treatment of advanced prostate cancer and other malignancies. However, in TGCT, with incidence peaking in the third decade, it is imperative that treatment be focused not only on a cure, but also on long-term benefit.

Competing interests: The authors declare no competing financial or personal interests.

This paper has been peer-reviewed.

\section{References}

1. Townsend JS, Richardson LC, German RR. Incidence of testicular cancer in the U.S., 1999-2004. Am J Mens Health 2010;4:353-60. http://dx.doi.org/10.1177/1557988309356101

2. Garner MJ, Turner MC, Ghadirian P, et al. Epidemiology of testicular cancer: An overview. Int I Cancer 2005;116:331-9. http://dx.doi.org/10.1002/iic.21032

3. Peckham M, Barrett A, Mcelwain T, et al. Combined management of malignant teratoma of the testis. Lancet 1979;314:267-70. http://dx.doi.org/10.1016/S0140-6736(79)90288-5

4. Tyrrell CJ, Peckham MJ. The response of lymph node metastases of testicular teratoma to radiation therapy. Br J Urol 1976;48:363-70. Available at: http://www.ncbi.nlm.nih.gov/pubmed/990684. Accessed July 15, 2014. http://dx.doi.org/10.1111/j.1464-410X.1976.tb06654.x

5. Joly F, Héron JF, Kalusinski L, et al. Quality of life in long-term survivors of testicular cancer: A populationbased case-control study. J Clin Oncol 2002;20:73-80. http://dx.doi.org/10.1200/JC0.20.1.73

6. Oldenburg J, Fosså SD, Nuver J, et al. Testicular seminoma and non-seminoma: ESMO clinical practice guidelines for diagnosis, treatment and followup. Ann Oncol 2013;24:vil25-32. http://dx.doi. org/10.1093/annonc/mdt304

7. Shah $\mathrm{SK}$, Lui $\mathrm{PD}$, Baldwin, $\mathrm{DD}$, et al. Urothelial carcinoma after external beam radiation therapy for prostate cancer. J Urol 2014;175:2063-6. http://dx.doi.org/10.1016/S0022-5347(06)00324-7

8. Thiissens KJ, van Ginkel R, Suurmeijer AH, et al. Radiation-induced sarcoma: A challenge for the surgeon. Ann Surg Oncol 2005;12:237-45. http://dx.doi.org/10.1245/AS0.2005.03.041

9. Travis LB, Fosså SD, Schonfeld SJ, et al. Second cancers among 40576 testicular cancer patients: Focus on long-term survivors. J Natl Cancer Inst 2005;97:1354-65. http://dx.doi.org/10.1093/inni/dij278

10. Zagars GK, Ballo MT, Lee AK, et al. Mortality after cure of testicular seminoma. J Clin Oncol 2004;22 :640-7. http://dx.doi.org/10.1200/JC0.2004.05.205

11. Murray EM, Werner D, Greeff EA, et al. Postradiation sarcomas: 20 cases and a literature review. Int J Radiat Oncol Biol Phys 1999;45:951-61. http://dx.doi.org/10.1016/50360-3016(99)00279-5

Correspondence: Dr. Tadeusz Kroczak, University of Manitoba, Winnipeg, MB, Canada; umkrocza@cc.umanitoba.ca 